\title{
Psychological Effects of Early Gentling on the Subsequent Ease of Handling in Lambs
}

\author{
Katsuji UETAKE, Seiko YAMAGUCHI and Toshio TANAKA \\ School of Veterinary Medicine, Azabu University, Sagamihara-shi 229-8501, Japan
}

(Received April 19, 2000 ; Accepted July 11, 2000)

\begin{abstract}
Four lamb twin sets were divided into two treatment groups for 7 days of handling at the age of 4 days. Gentled lambs were handled for $10 \mathrm{~min}$ in the suckling pen during morning routines. Other lambs of their twins were ignored when they approached the handler. The ease of handling in each lamb was assessed once a week from 2 to 16 weeks of age using a five-scale score in five components of the weighing procedures : chase, capture, haul, restraint and release. The synthetic obedient scores based upon those scores in the components were calculated ; the lower the score, the more obedient the animal. Occurrence of bleating during the procedures was counted. The synthetic obedient scores (Mean \pm SD) of gentled and ignored lambs were $4.4 \pm 3.0$ and $9.6 \pm 4.4(P<0.01)$, respectively. This result confirmed that a brief gentling of the lambs for the first 10 days after birth can improve their subsequent ease of handling. It was also indicated that the ease of handling could be emotionally improved by reducing a lamb's fear of humans and/or aversion to isolation. Gentling at age 4-10 days had, on the other hand, no apparent effect on body weight gain and the number of bleats reflecting the expression of a high level of fear.
\end{abstract}

Animal Science Journal 71 (5) : 515-519, 2000

Key words : Lamb, Ease of handling, Early experience, Fear

Some studies on sheep, goats and cattle, as reviewed by Le Neindre ${ }^{8}$, have shown that a lack of human contact at a young age leads to the animals being fearful and sometimes even aggressive towards their caretakers. Previous studies have shown that gentling is a pleasant procedure which improves subsequent human-sheep interactions $\mathrm{s}^{2-4,11}$. In these studies, physiological $^{3)}$, biochemical ${ }^{2,4)}$ and behavioral ${ }^{3,4,11)}$ pa- $^{2}$ rameters are measured as indicators of an aversion or stress of the sheep to human interactions. Of these parameters, behavioral responses are often the most obvious indicator that an animal is experiencing difficulty in coping with a problem such as environmental change ${ }^{1)}$.

Recent research concerning sheep ${ }^{10)}$ and cattle ${ }^{6,7)}$ have indicated a sensitive period of early cognition of newborn lambs and calves in the first 3 days after birth. In the sheep industries, natural delivery and nursing by ewes is widely accepted, and early handling procedures of lambs such as fixing an ear tag or cutting a tail is usually performed after letting them drink colostrum in the first 2 or 3 days after birth ${ }^{(4)}$.

In this study, gentling at age 4-10 days was investigated as a possible method of improving subsequent ease of handling. The psychological effects of early gentling were also analyzed.

\section{Materials and Methods}

For the first 10 days after birth, four twins Suffolk lambs were separately reared with their dams in suckling pens. The four lamb twin sets were divided into two treatment groups for 7 days of handling at the age of 4 days. One group of 4 animals was exposed daily for $10 \mathrm{~min}$ to gentle handling in the pens, while the other group of 4, used as a control, was exposed to no handling and was ignored even though they were in

Corresponding : Katsuji UETAKE (fax : +81 (0) 42-769-1692, e-mail : uetake@azabu-u.ac.jp) 
UETAKE, YAMAGUCHI and TANAKA

Table 1. Treatment, dam, subject number, sex, birth date and birth weight of lambs

\begin{tabular}{cccccc}
\hline Dam & Subject & Treatment & Sex & Birth date & Birth weight \\
\hline A & L1 & Gentled & Male & 21 Feb. '99 & $4.8 \mathrm{~kg}$ \\
& L2 & Non-gentled & Female & & 4.5 \\
\hline B & L3 & Gentled & Male & 23 Feb. '99 & 5.3 \\
& L4 & Non-gentled & Female & & 5.0 \\
\hline C & L5 & Gentled & Castrated Male & 26 Feb. '99 & 4.6 \\
& L6 & Non-gentled & Castrated Male & & 5.0 \\
\hline D & L7 & Gentled & Castrated Male & 3 Mar. '99 & 5.4 \\
& L8 & Non-gentled & Female & & 5.0 \\
\hline
\end{tabular}

the same suckling pen with their twins. The gentle handling consisted of some physical contact, such as stroking or rubbing, on the neck and shoulders or quiet or soft vocalizations. The same experimenter who sat in the pens performed the handling. The daily routine management was performed in the same way for the two groups. The sex of the subjects was balanced between the groups (Table 1).

The body weight of the lambs was measured in random order once a week from 2 to 16 weeks of age (until weaning). The ease of handling in each lamb was assessed using a five-scale score : the lower the score, the more obedient the animal. Assessment was carried out in five contexts of measuring operations : chase, capture, haul, restraint and release. The contexts are listed below.

\section{(1) Chase}

The lamb was chased through a yard and a shed by the experimenter.

\section{(2) Capture}

The lamb was caught and its movement was restricted for a moment.

\section{(3) Haul}

The lamb was hauled to the weighing scale situated at the end of the side race in the shed.

\section{(4) Restraint}

The lamb was confined on the weighing scale during measuring.

\section{(5) Release}

The lamb was released to the flock after measuring. The synthetic obedient score was calculated for Anim. Sci. J. 71 (5) : 515-519, 2000 each lamb by summing up all the scores in the five contexts to compare the overall level of easiness of the subjects.

The daily gain (DG) of each lamb was calculated from 2 to 15 weeks of age. The number of times each lamb bleated was counted during each time of measuring.

Repeated-measures analysis of variance (ANOVA) ${ }^{15)}$ was performed with a model including 2 betweensubject effects of Dam and Treatment and 1 withinsubject effect of Age on the synthetic obedient score. As for the number of bleats and the DG, the same repeated ANOVA model was applied.

A factor analysis ${ }^{15)}$ was used to find out the psychological factors that potentially cause difficulty in handling lambs. Initial factors were extracted by principal component analysis with prior communality estimates set to 1.0. The number of common factors was determined according to the scree criterion that considers the difference between successive eigenvalues. The rotated factor pattern was calculated with orthogonal varimax rotation. Factor scores were estimated for each lamb.

\section{Results}

While there was no apparent Dam and Age effect, the effect of the Treatment was significant $(P<0.01)$ for the synthetic obedient score (Table 2). Neither the Dam $\times$ Age nor Treatment $\times$ Age interaction was significant. The mean synthetic obedient scores ( $\pm \mathrm{SD}$ ) of the gentled and control lambs were $4.4 \pm$ 
Ease of Handling in Lambs

Table 2. Analysis of variance for the synthetic obedient score

\begin{tabular}{lrrr}
\hline \hline \multicolumn{1}{c}{ Effect } & \multicolumn{1}{c}{ df } & \multicolumn{1}{c}{ MS } & $\operatorname{Pr}>$ F \\
\hline Between subjects & 7 & & \\
$\quad$ Dam & 3 & 130.333 & 0.09 \\
Treatment & 1 & 811.200 & 0.01 \\
Subject & 3 & 22.956 & \\
Within subject & 112 & & \\
Age & 14 & 18.169 & 0.06 \\
Dam $\times$ Age & 42 & 9.392 & 0.56 \\
Treatment $\times$ Age & 14 & 9.700 & 0.48 \\
Error & 42 & 9.860 & \\
\hline
\end{tabular}

$\mathbf{R}^{2}=0.832$.

Mean synthetic obedient score $( \pm \mathrm{SE})=7.03 \pm 3.14$.

Table 3. Analysis of variance for daily gain

\begin{tabular}{lrll}
\hline \multicolumn{1}{c}{ Effect } & \multicolumn{1}{c}{ Df } & MS & $\operatorname{Pr}>\mathrm{F}$ \\
\hline Between subjects & 7 & & \\
$\quad$ Dam & 3 & 0.003 & 0.60 \\
Treatment & 1 & 0.013 & 0.21 \\
$\quad$ Subject & 3 & 0.005 & \\
Within subject & 112 & & \\
Age & 14 & 0.059 & 0.01 \\
Dam $\times$ Age & 42 & 0.007 & 0.53 \\
Treatment $\times$ Age & 14 & 0.003 & 0.97 \\
Error & 42 & 0.007 & \\
\hline
\end{tabular}

$\mathbf{R}^{2}=0.795$.

Mean daily gain $(\mathrm{kg} /$ day, $\pm \mathrm{SE})=0.19 \pm 0.09$.

3.0 and $9.6 \pm 4.4$, respectively. This result showed that gentling at age 4-10 days can improve subsequent ease of handling.

On the other hand, the effect of the Treatment was not significant for the DG (Table 3) and the number of bleats (Table 4). The Age effect was significant $(\mathrm{P}<0.01)$ for the $\mathrm{DG}$ and there was a significant $(\mathrm{P}<$ 0.05 ) difference between 2 (Mean $\pm S D, 0.33 \pm 0.08$ $\mathrm{kg} /$ day) and $8(0.10 \pm 0.07)$, and $6(0.32 \pm 0.06)$ and 8 weeks of age.

The scree plot that bent at the third eigenvalue showed two factors present (Table 5). The scores for chase, capture, haul and release had large loadings
Table 4. Analysis of variance for the number of bleats

\begin{tabular}{lrll}
\hline \multicolumn{1}{c}{ Effect } & df & MS & Pr $>$ F \\
\hline Between subjects & 7 & & \\
Dam & 3 & 5.344 & 0.55 \\
Treatment & 1 & 0.300 & 0.84 \\
Subject & 3 & 6.278 & \\
Within subject & 112 & & \\
Age & 14 & 1.133 & 0.17 \\
Dam $\times$ Age & 42 & 1.178 & 0.09 \\
Treatment $\times$ Age & 14 & 0.657 & 0.62 \\
Error & 42 & 0.778 & \\
\hline
\end{tabular}

$\mathrm{R}^{2}=0.771$

Mean number of bleats (times, \pm SE) $=0.72 \pm 0.88$.

Table 5. Factor analysis for the ease of handling in the measuring operations of body weight

\begin{tabular}{lccc}
\hline \multicolumn{4}{c}{ Loading } \\
\hline Context & 1st Factor & 2nd Factor & Commu $^{\mathrm{a}}$ \\
\hline Chase & 0.96 & 0.27 & 0.99 \\
Capture & 0.92 & 0.37 & 0.98 \\
Haul & 0.89 & 0.43 & 0.97 \\
Release & 0.89 & 0.45 & 1.00 \\
Restraint & 0.36 & 0.93 & 0.99 \\
\hline Eigenvalue & 3.46 & 1.47 & \\
Proportion & 0.69 & 0.29 & \\
Cumulative & 0.69 & 0.99 & \\
\hline
\end{tabular}

${ }^{a}$ Commu. $=$ communality.

on the first factor so that the first factor was interpreted as "fear of humans". The score for restraint had a large loading on the second factor so that the second factor was interpreted as "aversion to isolation". The proportion of variation represented by the first and second factor was 0.69 and 0.29 , respectively, and the cumulative proportion of variation was 0.99 (Table 5). The final communality estimates of the 5 contexts were all more than 0.98 (Table 5), showing that the ease of handling in each context was well explained by these two factoes.

Comparison of the factor scores between the gentled lambs and their control twins demonstrated 


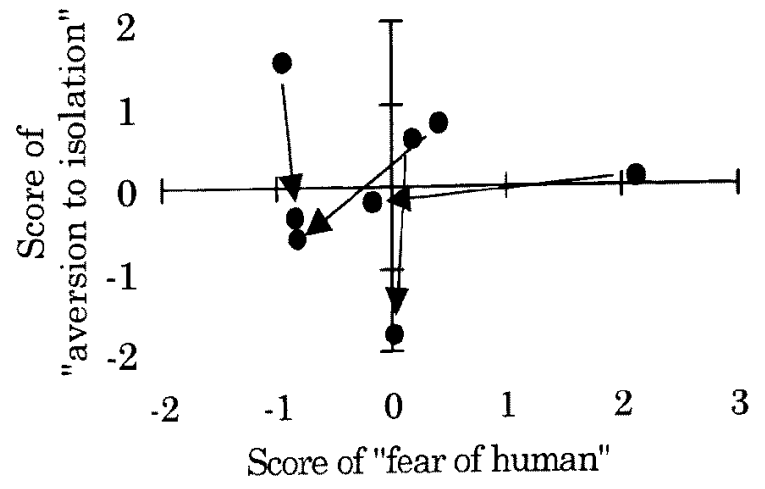

Fig. 1. Plot of factor scores in each lamb. Arrow lines are drawn from control lambs to their gentled twins.

three influencing patterns of gentling, that reduce "fear of humans", "aversion to isolation" and both of them (Fig. 1). This result suggested that the psychological effects of early gentling would differ between individuals.

\section{Discussion}

Although Markowitz et al. ${ }^{10)}$ reported that human contact at age 1-3 days reduces a lamb's timidity to people rather than at age 3-9 days, the result of this study indicated that gentling even at age 4-10 days can improve subsequent ease of handling. Concerning industrial implication, interacting with lambs from the first to second week of age would be more practical from the standard point that ordinary management practices, such as fixing an ear tag and cutting a tail, are usually performed within that period of time ${ }^{14)}$.

Kosako and Imura ${ }^{7)}$ reported that early handling for 3 days after birth reduces the excitability of cattle captured by caretakers. In this study, it is interpreted that a lamb's ease of handling in the context of measuring body weight is dependent on two prime factors, "fear of humans" and "aversion to isolation". Isolation from conspecifics, physical restraint, surprise and the presence of a human is well introduced as experimental situations to induce fear in sheep ${ }^{13,16)}$.

It is indicated that the number of high-pitch bleats is one of the parameters reflecting the expression of a high level of fear ${ }^{12)}$, but most lambs in this study hardly bleated all through the experiment (Mean number of bleats $\pm \mathrm{SE}, 0.72 \pm 0.88$ times). This suggests that the level of fear in this experiment was not so high even in the non-gentled lambs. It is recommended for practicality that sheep should be moved through yards and sheds in the same direction and via the same route for management operations ${ }^{5)}$. Thus, habituation to the routine measuring procedure is another possibility. The mild stress in this experiment could explain why the difference in the number of bleats and body weight gain was not significant between the gentled lambs and their control twins.

The growth of lambs is dependent upon not only artificial management procedures but also the maternal performance ${ }^{14)}$. It was of no concern to the dams that their lambs had ever been gentled or not by humans. The twin lambs were equally fed during daily management so that no differences in the growth rate seemed quite natural.

In the present experiment, five limited contexts of human-sheep contacts were investigated. So more extensive studies are required to determine the psychological effects of gentling on the full range of humansheep interactions. Rushen ${ }^{13)}$ reported that sheep show ordinal preference for treatments of routine handling operations, in order of decreasing preference : human contact, physical restraint in the presence of sheep, isolation, capture in isolation, and inversion in isolation, for example.

The results of this study suggest that psychological effects of early gentling could differ between individuals. In order to understand the cause of individual differences in the temperament of domestic animals, the studies of behavioral genetics and development has been carried out (well reviewed by Manteca and Deag $^{9)}$ ). Innate sensitiveness or readiness to early experiences would be particularly relevant to the development of individual differences.

In conclusion, gentling at age 4-10 days can improve the subsequent ease of handling by reducing the fear of humans and/or aversion to isolation, but does not have significant effects on the body weight gain of lambs.

\section{References}

1) Broom DM, Johnson KG. Stress and Animal 
Ease of Handling in Lambs

Welfare. 1st ed. 88-92. Champman \& Hall. London. 1993.

2) Hargreaves AL, Hutson GD. The stress response in sheep during routine handling procedures. Applied Animal Behaviour Science, 26:83-90. 1990.

3) Hargreaves AL, Hutson GD. The effect of gentling on heart rate, flight distance and aversion of sheep to a handling procedure. Applied Animal Behaviour Science, $26: 243-252.1990$.

4) Hargreaves AL, Hutson GD. Some effects of repeated handling on stress responses in sheep. Applied Animal Behaviour Science, 26 : 253-265. 1990.

5) Hutson GD. An evaluation of some traditional and contemporary views on sheep behaviour. Wool Technology and Sheep Breeding, 29 : 3 6. 1981.

6) Jago JG, Krohn CC, Matthews LR. The influence of feeding and handling on the development of the human-animal interactions in young cattle. Applied Animal Behaviour Science, 62: 137-151. 1999.

7) Kosako T, Imura $T$. Effect of handling treatment during three days after birth on the subsequent reaction to humans in Japanese Black calves. Animal Science Journal, 70 : J409-J414, 1999.

8) Le Neindre P, Boivin X, Boissy A. Handling of extensively kept animals. Applied Animal Behaviour Science, 49 : 73-81. 1996.
9) Manteca X, Deag JM. Individual differences in temperament of domestic animals : A review of methodology. Animal Welfare, 2 : 247-268. 1993.

10) Markowitz TM, Dally MR, Gursky K, Price EO. Early handling increases lamb affinity for humans. Animal Behaviour, 55 : 573-587. 1998.

11) Mateo JM, Estep DQ, McCann JS. Effects of differential handling on the behaviour of domestic ewes (Ovis aries). Applied Animal Behaviour Science, 32 : 45-54. 1991.

12) Romeyer A, Boussou MF. Assessment of fear reactions in domestic sheep, and influence of breed and rearing conditions. Applied Animal Behaviour Science, 34 : 93-119. 1992.

13) Rushen J. Aversion of sheep for handling treatments : Paired-choice studies. Applied Animal Behaviour Science, $16:$ 363-370. 1986.

14) Saito T, Kono H. A guideline on sheep. In : Guidebook on Sheep and Goat. 34-43. Japan Sheep Association. Tokyo. 1994.

15) SAS Institute. SAS/STAT user's guide. Version 6. SAS Institute Inc. Cary. 1994.

16) Vandenheede M, Bouissou MF. Sex differences in fear reactions in sheep. Applied Animal Behaviour Science, $37: 39-55.1993$. 